\title{
In situ Investigation of Phase Transformation of Anatase Into Rutile
}

\author{
Dongsheng $\mathrm{Li}^{1}$
}

1. Fundamental \& Computational Sciences Directorate, Pacific Northwest National Laboratory, Richland, WA, USA

Titanium dioxide $\left(\mathrm{TiO}_{2}\right)$ has been used in various applications such as photocatalysts[1], solar generation of hydrogen[2], methanol fuel cells[3], anodes for lithium rechargeable batteries[4], and photovoltaic cells[5]. It has been reported that rutile exhibits high rates of recombination in comparison to anatase[6]. Some mixed phases, such as Degussa P-25, have high photoactivity due to the transferring of electrons from rutile to anatase trapping sites, which hinders the charge recombination[7, 8]. Moreover, while anatase is the stable phase at small $(\mathrm{nm})$ particle size, rutile is the stable phase of bulk $\mathrm{TiO}_{2}$ [9] . In addition, the formation of branched $\mathrm{TiO}_{2}$ appears to involve a process of anatase attachment to rutile nanowires[10]. Thus, controlling the phase of $\mathrm{TiO}_{2}$ is critical for uncovering phase-function relationships and producing functional materials. The goal of this work is to investigate the mechanism of the transformation from anatase to rutile in the solid state by in situ HRTEM/HRSTEM and to reconstruct the transformation in 3-D at the atomic level. The transformation from anatase into rutile is well known, however, the mechanism by which it occurs, its dependence on particle size, shape and proximity to other particles of anatase or rutile, and the factors that trigger its occurrence are not understood. Here we perform high-resolution TEM/STEM imaging experiments of anatase particles in order to observe their transformation into the rutile phase in solid state and establish an understanding of this important nanomaterial phase transformation and the atomic-scale processes that lead to particle-wire integration when the precursor particles and growing wire have distinctive structures

In this work, we studied the transformation of anatase particles into rutile without oriented attachment at temperatures of $600^{\circ} \mathrm{C}$ to $900^{\circ} \mathrm{C}$. In our preliminary in situ TEM experiments, we observed morphological changes at low and high magnification (Figs. 1 and 2, respectively). Figure 3 presents time sequences of in situ HRTEM images of $\mathrm{TiO}_{2}$ particles during the process of phase transformation. The most intriguing result from this preliminary work, is that we observed what appears to be a previously unreported "intermediate" phase consisting of square shaped particles as seen in Fig. 2. [11]

\section{References:}

[1] S. Kwon et al, Critical Reviews in Environmental Science and Technology, vol. 38, pp. 197-226, MayJun 2008.

[2] T. Puangpetch et al, International Journal of Hydrogen Energy, vol. 35, pp. 12428-12442, 2010.

[3] S. Y. Huang, et al, Journal of the American Chemical Society, vol. 131, pp. 13898-+, 2009.

[4] M. Wagemaker, A. P. M. Kentgens and F. M. Mulder, Nature, vol. 418, pp. 397-399, Jul 252002.

[5] J.-K. Oh et al, Chemistry of Materials, vol. 22, pp. 1114-1118, Feb 92010.

[6] Y. Yamada and Y. Kanemitsu, Applied Physics Letters, vol. 101, Sep 242012.

[7] A. A. Gribb and J. F. Banfield, American Mineralogist, vol. 82, Jul-Aug 1997.

[8] W. Peng et al, Nanotechnology, vol. 22, Jul 82011.

[9] A. S. Barnard, P. Zapol and L. A. Curtiss, Journal of Chemical Theory and Computation, vol. 1, Jan-Feb 2005.

[10] D. Li et al, Crystal Growth \& Design, vol. 13, pp. 422-428, Feb 2013.

[11] The authors acknowledge funding from Basic Energy Science (BES), Department of Energy (DOE) and the user facilites of EMSL at PNNL and Molecular Foundry at LBNL. 


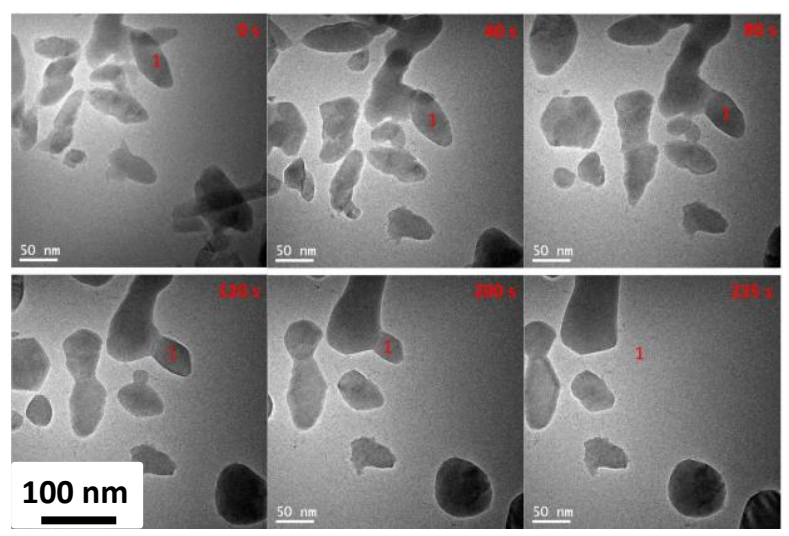

Figure 1. TEM images at low magnification of $\mathrm{TiO}_{2}$ particle morphologychange with time.

Particle 1 is marked in the images, which is absorbed by the adjacent particle. Scale bar is same for all images

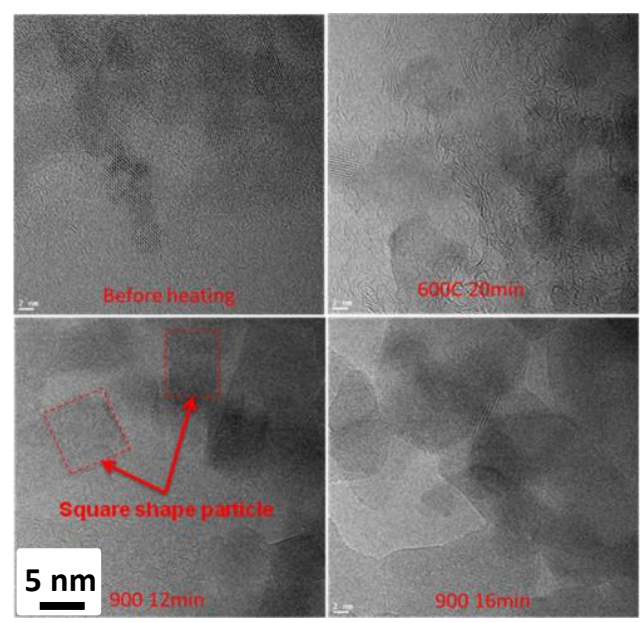

Figure 2. TEM images at high magnification of $\mathrm{TiO}_{2}$ particle

morphology change with time. (note: images are not recorded at the same location) Scale bar is same for all images

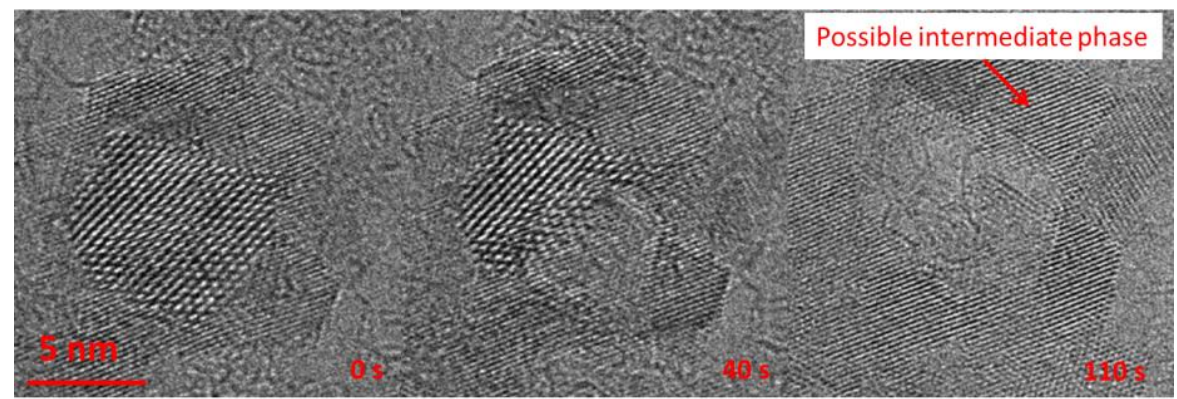

Figure 3. Time sequences of HRTEM images of $\mathrm{TiO}_{2}$ particle during the process of phase transformation. Scale bar is same for all images 